\title{
How healthy are we? \\ Narratives of experiential health from a village of Western Nepal
}

\section{Bamdev Subedi}

\section{Abstract}

It has become a custom citing development reports, which show remarkable progress in some of the health indicators, to signify the higher quality of life achieved over the years. The human development datasets, for instance, present impressive progress in terms of decreased mortality, increased life expectancy, higher literacy and falling poverty which is synonymous to a higher standard of living. With the amazing success in medical science, advancement in therapy and surgery, and prevention and control over some of the dangerous diseases, we are bound to believe that we have achieved much, and there is no question whether the overall health condition has been worsened in the last few decades. The real life experience of local people, however, challenges this fact and compels us to reflect on "are we really healthy than before?" Drawing from a qualitative study conducted in a district of midwestern Nepal, this paper presents people's narratives to deepen our understanding of how people in an urbanizing village experience health. The paper recognizes the deteriorating health experience of the people which has primarily resulted from a loss of local health traditions exacerbated by the current change and development.

Keywords: change and development, experiential health, local health traditions, narratives, Nepal 


\section{Introduction}

The vast body of literature highlights the remarkable progress in health achieved over the years (UNDP, 2010). We are bound to believe that, indeed, we have achieved much in health and wellbeing, and we are striving for ever higher achievement. The repeated assertion of improved health indicators in periodic survey and development reports leave no room for doubt. We have compelling reasons to believe that we are moving from poverty to prosperity, from illiteracy to higher educational attainment and from ill health to good health (UNDP, 2015; WHO, 2015; World Bank, 2016). Citation of latest survey and development reports, which show remarkable progress, has become a customary to base our argument of quality of life and to show the progress made over the years. The human development datasets, for instance, present impressive progress in terms of decreased mortality, increased life expectancy, increased level of education, decreased poverty and a higher standard of living. "In health, unprecedented progress has been made in reducing maternal and child mortality and in the fight against infectious diseases," writes Dr. Margaret Chan, in the preface of Health in 2015: From MDGs, Millennium Development Goals to SDGs, Sustainable Development Goals (WHO, 2015). After MDGs, we have entered into an era of SDGs with a new set of goals and targets of development which will be measured with a new yardstick.

Viewing the development of science and technology and amazing success in therapeutic advancement and surgery (such as open heart surgeries, transplant of livers and kidneys and other such landmarks) and successful treatment of complex and severe disease conditions, discovery of newer drugs, effective prevention and control over diseases (such as polio, malaria, leprosy, tuberculosis, HIV, SASH, Ebola, bird flu and dengue to name a few); we are bound to believe that indeed, we have made remarkable progress, and there is no question whether the overall health condition of the people has worsened over the years.

The story of Nepal is more or less similar to other countries. Despite the political turmoil, instability, and socio-economic constraints, Nepal has made impressive achievement in health over the last two or three decades. The efforts of Nepal got an international appreciation 
especially in achieving the targets of infant and maternal mortality rates (NPC \& UNDP, 2013, p. 3) and in the progress of HDI (UNDP, 2010 , p. 54). Indeed, the national data on health indicators show an impressive progress made over the years. For example, within a decade's time, maternal mortality ratio declined from 539 in 1996 (MoHP, GoN, New ERA, \& ICF International, 2007) to 229 per 100000 live births in 2009 (Suvedi et al., 2009). Between 1991 to 2011, the infant mortality rate declined from 106 to 40.5 per 1000 live births, total fertility rate from 5.3 to 2.5 children per woman, crude birth rate 41.6 to 21.8 per 1000 live births, crude death rate from 13.3 to 7.3 per 1000 live births) and life expectancy at birth increased from 54.2 years (male 55.0 and female 53.5) to 66.6 years (male 65.5 and female 67.9). The total literacy rate of six years and above population increased from 39.6 to 65.9 percent (CBS, 2014; CBS \& UNFPA, 2007). Poverty headcount rate also declined from 41.8 (in 1995/96) to 25.2 (in 2010/11) (CBS, 2014) and overall HDI improved from 0.316 in 1990 to 0.458 in 2011 (UNDP, 2010, 2011). This shift indicates to the progress and development. Of course, there are regional, ethnic, class, caste and gender disparities, and progress has been more visible in certain sections of the population (NPC \& UNDP, 2014). However, gross indicators are sufficient to explain that people are in better condition than ever before (UNDP, 2015, p. 56). With the planned interventions there is increased access to education and health care services. As a result, we have extended life expectancy, a higher percentage of literacy, low maternal and infant mortality, fewer children, small and happy family.

The real life experience of the local people, however, defy this fact and compels us to reflect on "are we really healthy than our forefathers?" They find it difficult to understand the meaning of the numbers but they can show the relationship between weak health and the declining local health traditions ${ }^{1}$. This questions

1. According to Priya \& Shweta (2010, p. xix) "local health traditions represent the practices and knowledge of the common people and folk practitioners who follow an oral tradition of learning and passing on of the knowledge through practice." Payyappallimana (2013, p. 101) uses the term 'local health traditions' to refer to "the geographical and ecosystem-specific practices, beliefs, customs, rituals related to health, nutrition or broader well-being passed on from one generation to another mostly in oral transmission." 


\section{6| Bamdev Subedi}

whether the much-lauded achievement in selected indicators are, in fact, the indicators achieved at the cost of other unspecified ones. Whether these indicators indicate real progress and development and do not contain elements of statistical excitement research hype and academic illusion or the politically correct explanations. The question is whether the progress has resulted in a healthy, happy and satisfied life of the population.

The paper attempts to understand how people look at these progress and development. The focus is on the health perceptions of the people, their understanding, and explanation. More importantly, the paper seeks to understand how people are experiencing their health. In so doing, the paper draws from a study conducted in a district of mid-western Nepal and presents narratives of the local people. In the dominant development discourse, these narratives have a very limited place, if at all. Nevertheless, these narratives are important since they represent a category which is often unheard or just ignored. The paper tries to give these narratives a space for further discussion. These are worth listening as these represent the counter statements against the 21 st - century material progress and well-being and at the same time challenge the dominant thinking.

\section{The setting}

\section{Methods}

One of the South Asian countries located between India and the Tibetan autonomous region of China, Nepal holds a unique sociopolitical history, natural beauty, and cultural diversity. Nepal is famous for its natural beauty not only because it houses some of the beautiful valleys and highest mountains including the Mount Everest but also because of the richness of biodiversity found across the plain, hill and mountain regions. Nepal is famous for some of the world heritage sites of cultural importance and cultural diversity. Nepal is home to 26.6 million people with more than 125 caste and ethnic identity, speaking 123 different languages as mother tongues and following ten different types of religions (CBS, 2012).

Nepal has experienced a rapid change and development in political, economic, social, cultural, environmental spheres in the last two or three decades. Nepal experienced political instability, first 
democratic movement (in 1990), Maoist armed conflict (1996-2006), second democratic movements and the end of Monarchy (2006) and a new Constitution in 2015. Similar to other countries, Nepal also experienced an effect of liberalization, commercialization and privatization since early 1990s. The private sector is growing and we can see a greater involvement of private sectors in health and education sectors. The health infrastructure increased and expanded, though there is urban concentration.

The national health care system is based on biomedicine (or allopathy). Aurveda and other alternative systems (including homeopathy, unani and naturopathy) are recognized as part of national health care system. Despite the wider existence, the local folk or indigenous systems have not been integrated in the national health care system. The development intervention has brought changes in agriculture, employment, transport and communication, health and sanitation in the local setting. The participants' narratives are the reflection of their experience of change and development in their context.

\section{The people and the place}

The study was conducted in a village cluster of Dang district which is located around 400 kilometers south-west of Kathmandu. The narratives were collected primarily from the people of Saudiyar, a village development committee (VDC) of Dang district. It takes two to three hours on foot and less than an hour by bus to Ghorahi, the nearest city and district headquarter from Saudiyar. The VDC is well connected by road transport and has experienced an urban influence. The area is populated mostly by Tharu followed by Chhetri, Brahmin, Magar, Dalits and half a dozen other castes and ethnic communities. The interaction between co-inhabited caste and ethnic communities, government intervention on health, involvement in political movements and emerging livelihood options have brought changes in their lives. There are visible changes in the socio-cultural life and health seeking behavior of the people. In the last couple of decades, the area has seen a rapid change in food production, consumptions and in the way of life. People are connected by transport and communication, radio and television, mobile and markets with access to modern agricultural inputs. Besides, the 


\section{8| Bamdev Subedi}

area is attracting people from neighboring districts. The main occupation is agriculture supplemented by animal husbandry. Here, a notable fact is that a number of youths work in Malaysia and Gulf countries as unskilled and semi-skilled laborers. The VDC source states approximately ten percent of the total population is in foreign employment (Saudiyar VDC, 2010). The remittance constitutes a significant share of family income in the village. Moreover, they are exposed to the outside world. They return home not only with money and modern gadgets (such as television sets, tablets, smartphones, and home appliances) but also with a different worldview.

\section{Data collection methods}

A qualitative approach was followed to collect data and information. The interview was conducted with community people, especially with elderly community members. Group interactions were conducted with female community health volunteers, cooperative members and school teachers. The interaction was on the local health issues and their perceptions of health. The participants were selected purposively and the participation was voluntary. The participants were from different class, caste, gender, educational and occupational backgrounds. However, most of them were elderly, male, literate and educated. The findings are presented in narrative forms. However, participants' names are not mentioned in the narratives to keep anonymity and protect their confidentiality.

The participants do not represent the whole population because most of them were aged 50 and above, educated and were selected purposively. This can be taken as a limitation of this study. There were counter-narratives as well, but the paper does not give them space. This may seem unbalanced and biased; however, the counternarratives represent the dominant narration which is beyond the scope of this paper. The dominant narration claims that we are on the right pathway of development, and it is useless and rather stupid to question the current human advancement and progress. In the dominant eyes, the present narratives are nothing more than an expression of a nostalgic of "good old days." Nonetheless, these field narratives have meanings which can help us understand local problems from local perspectives. I have tried to keep the narratives in their original forms, and they are also open to the readers' interpretation. 


\section{Results}

\section{Healthy: Who is healthy and who is not?}

Locally swasthya is used as an equivalent word for health and swostha as healthy. I began with the question "who is swostha?" The most common understanding is that a swostha is the one who can eat and work as usual. If someone is eating properly and doing dayto-day work properly, he or she is considered swostha. If someone is not eating properly or not doing work as usual, then the person is not considered swostha but aswostha. He or she may be ill or sick. If someone eats properly but does not show interest in work, he or she is not considered sick but alchhi (lazy). They describe that if one gets an illness or is diseased one doesn't feel hungry, and if one does not feel hungry one does not feel like eating and working or does not feel good or even cannot sleep well. So, to be healthy means to be chinta mukta (free from mental worries) and rista pusta (physically sound and strong). A person is considered healthy who has no worry, no pain, who can walk, work, eat, sleep and who is happy. A local pundit said that swostha is a word made of swa means 'self' and stha means 'being in the position of." Thus, swostha means "being in the position of oneself." This refers to a state of balance, completeness, and contentment.

This gives an idea of what they mean by healthy. However, the question is 'who is healthy?' I started with children: Are the children healthy? An educated elderly male participant on the questions of how healthy are the children responded, "The total immunity power of the present day children has been drastically lost. They cannot digest even a glass of pure milk; you need to mix a little water to make it digestible." He was a local social worker, quite familiar with village activities continued, "The village milkmen are experienced enough. They first mix a little water into pure milk and then go to sell. Both are happy, the milk seller and the buyer. The sellers are making money, and the buyer are getting the milk which they can digest." He gave a reference of a popular folk song Garnu garyau Balaram bhaisi palera, khanti dudhma pani halera (Wow! Mr. Balaram, you did a great job by keeping buffalos and selling milk by mixing water). The song points to the current adulteration practices presenting a case of milkman and a woman hotelier. His main point 


\section{0| Bamdev Subedi}

was they cannot get pure milk; even if they get, they cannot digest. Hence, they are not so healthy. By definition, a healthy child must be able to digest pure milk. The 'khayo, piyo, pachayo' (ate, drank, digested) is what is expected from a healthy person. A healthy person must have "digestion capacity of various types of food" (Subedi, 2011, p. 104).

Another elder participant, who saw no difference even among the younger generations, explained using proverbs and popular sayings, "You see, now the baisalu thiti (grown up girls) also look like phunga udeko (pale and anemic complexion), and they use bogus fairness cream to look beautiful and attractive. But natural beauty does not come from fairness cream. It comes from inside, from the nourished body. To be naturally beautiful, attractive and strong you need to be healthy. The facial cream for external use does not make you healthy. You need to eat nutritious food and digest them. Fairness cream is like dudh khaye kahile laagne, khoyabirke khaye ahile (there is uncertainty when the drinking milk results but the fairness cream is like alcohol; it results quickly, "in just 14 days" (as advertised)." He also sang a line of uhile bajeko palama paisa ganthe dalama, ahile hamro palama makai chhana dalama (earlier in grandfather's time, people used to count coins in baskets, now in our times we don't even have maize in the basket). He added with a smile, "It does not matter whether there is grain or not in your basket but you better need to keep a good sized fairness cream in your make up box!"

Interestingly, the understanding of a healthy body, which is also characterized as moto ghato (fat and stout) by most participants, a woman participant, however, expressed a different view. She presented her logic, "moto-ghato does not necessarily mean a healthy body. If you get phokse masu (flesh without weight) look like a broiler hen kept in Mr. B's poultry form, or look like a pauroti (a type of light bread) you are not healthy. You eat bekarka cheese (nonsense things) and how can be there khadilo masu (weighty flesh). You need to have naturally produced tagatilo (nutritious) food to be strong and healthy." Few others who were also listening to her seemed convinced. A study conducted in Kathmandu valley also shows the similar perception of nutritious foods and healthy body (Subedi, 2002). 


\section{Dhaulagiri Journal of Sociology and Anthropology Vol. 10, $2016 \mid 131$}

\section{Food: What is good and what is bad?}

Healthy body and healthy population is not possible without adequate nutritious food. The participants shared their experience of change in local food culture and food practices. They have their own understanding of good, not so good and bad food. There was an intense discussion about the pure and adulterated food items. One of the participants presented a situation where there is almost impossible to get pure things. He asked, "What is sudda (pure or natural) nowadays?" and answered, "You will find adulteration everywhere." He was of the view that the misawot (adulteration practices) can be found in many items, even in medicine. He illustrated an example, "You know, first they sell a shampoo, and that causes dandruff, and again they sell anti-dandruff shampoo that prevents dandruff but starts breaking hair or making you bald and then comes another product. You will get rid of one thing but get another. Same example applies in medicine. Doctor gives you a drug that cures your one problem but at the same time you will get another problem. There is no ultimate solution in modern drugs. That is why this is called dawai (suppress). The doctor's medicine can suppress down your problem but cannot not remove it completely."

Pointing to a change and development in food practices a school teacher said, "Now we have cold drinks instead of mohi (butter milk), chau chau (packaged noodles), pauroti (bread) and biscuits instead of makai- bhatta (maize- soybean), chana (gram) and homemade chapatti. We have many packaged food items in the markets and snacks like chaumin in the restaurants. Our kids are addicted to chau chau and adults to chaumin, and this has affected their health. The fast food restaurants use unnecessary and potentially harmful spices such as ajinomoto, black pepper, colors etc. Take choumin and the next day when you sit for toilet you will remember the burning test. Those who used to drink jaand (fermented rice) or raksi (home brewed liquor) have started [to drink] bottled alcohol. You tell me where does the tagat (strength) come from? From cold drink or buttermilk, from noodles or maize-gram, from fermented rice or bottled alcohol?"

Another participant affirmed this view and added further, "It is hard to get pure things nowadays. Even if we keep cows for milk, we won't 


\section{2| Bamdev Subedi}

get pure, truly. The cows and buffalos are also getting chemicalized grass and fodders. You know, we are feeding them differently than before. These days, cow dung smells bad, and I doubt that you can get pure cow urine [to be used as medicine]. We have been using chemical fertilizers and pesticides/insecticides in our agricultural fields. We are all chemicalized."

The association of food practices with healthy and strong body is very common. An experienced birth attendant shared her experience, "Today's girls and women are not rista pusta (physically sound and strong). They are dubla and kamjor (skinny and weak). They cannot give birth on their own. They need to go to hospital for operation [C-section]. In our times, we used to give birth on our own, sometimes while we were working [in the field]. There were some brave women who not only gave birth while they were in the jungle but also return home with newborn baby along with a bundle of fodder or firewood. There used to be short betha lagne (labor pain). Now, they confuse us whether it was nakal pareko (false) or sachikai betha lageko ho (it is real labor)."

Why were earlier women brave? On this question, her response was, "In those time, they used to have pure and natural things. They used to make jwano ko jhol (literally 'soup of ajwain' made in pure ghee adding other spices and ingredients including turmeric), okhte pitho (literally 'curative flour' prepared in ghee mixing a variety of ingredients, for delivered woman and lito (a kind of flour made from rice, gram, and wheat) for small children and satu (ready to use flour made from barley, maize, wheat, gram and chickpeas) for all time use. We didn't need to go to hospitals for minor illnesses because we used to make something in our home." These practices are still found in some families. Each family has some knowledge and skills to deal with various health problems. However, she was pointing to the erosion of family knowledge system.

The participants unanimously agree on the emergence of hazardous condition. A participant, who was from indigenous leader's family locally known as Mohataun, elaborated his experience and views, "People of our time contact disease more frequently than our forefather's time. There are new kinds of diseases arriving. Our food production has been changed. Food habit has been changed. We left 
golbheda (local tomato) and started tamatar (local name for a hybrid variety of tomato). We left tilki, jeera masino and simtharo (local varieties of rice) and started new hybrid seed of which we even don't know names. We left Dangali aalu (local potatoes) and started different ones. We plant bemausami (off-seasonal) vegetables and we have also become bemausami. Today we use chemical fertilizers and spray pesticides such as thiodine and metacid. We consume hybrid vegetables contacted with chemicals and toxic substance. Who will fall ill, if not us? No one! We are having different problems, and we are not healthy because we fall ill more often and we are always in tension (original English)." He also claimed that some people have developed problems of bath rog (joint pains or arthritis) for consuming one of the kinds of rice recently introduced. Most participants agreed that it is better not to consume such rice soon after the production but to wait a year or two.

Some of the participants also viewed that the cemented house also causes joint pains or arthritis, especially when one does not use footwear inside the cemented house floor for a long time. However, people do not use footwear inside home because this is not culturally acceptable behavior. Some participants also pointed to the changes in home appliance, for instance, using plastic water buckets and mug instead of gagri (copper water vessels) and amkhora (bronze jug) and clothing behavior for example using modern style silky cloths instead of traditional cotton cloths. Pointing to the declining home based herbal practices another participant put, "We have forgotten the value of local medicinal herbs. We have left home based health practices. We know how to prepare zinger or tulasi (holy basil) tea to control running nose but we have no more interest in it. Rather we buy whatever is available in medical dispensaries. Even if we prepare and use local herbs that are not likely to work because chemicalized body needs chemicalized medicine: The injection and high dose hard drugs. Alas! We need medicine even for running nose!"

They have reasons to say that they are not healthy than their forefathers. By saying this they are pointing to the health hazards associated with the changes in agricultural activities, food practices and the local health traditions. 


\section{4| Bamdev Subedi}

\section{Tradition: What is there and what is missing?}

The local health traditions are withering. In the families, the elders are not consulted. Sons, daughters, and daughters-in-law do not listen to (great) grandmothers, grandfathers, mothers-in-law or fathers-in-law and do not show an interest to learn from them. This is also because of the changing structures of family size, as society is moving from joint to unitary families. Present day family members live in different places: some of the members go far from the village in search of education, employment, and business. The changes in enculturation and socialization process also impacted on the transfer of family knowledge system. The narratives signal that there is a low level of transfer of knowledge from old generation to new generation. The local knowledge transmission has been slowed down because of various reasons. The folk or indigenous health practices have also been affected and there are concerns over preserving locally available medicinal plants, protecting indigenous health practices, promoting of indigenous knowledge systems and revitalizing local health traditions (Bode \& Hariramamurthi, 2012; Budhathoki \& BC, 2008).

A participant who also provides astrological services to the people from far and wide shared, "We have left to plant bar and pipal (ficus religiosa and ficus bengalensis), make chautaro (resting place), pokhari (water ponds). Rather we have cut down these trees, filled out ponds and break down the public places in the name of development. We destroy the existing structures and we call it bikas (development). We had many good things [in our cultural tradition], but we saw only bad things and didn't bother to understand and follow them. Tell me, is it bad to hold view of basudaiva kutumbakam (the whole world is one single family), sarve bhavantu sukhina, sarve santu niramaya (may all become happy, may all be free from illness), atithi devo vaba (guests are like Gods), ek nari bramachari (one is bachelor who is faithful to a single woman). We have got a problem of AIDS because we didn't follow the rule of ek nari bramachari. And it seems we are not going to follow it." He continued with a smile, "We would rather follow condoms. Because we see solutions in condoms. A condom is a symbol of development. We are happy because we are provided with condoms!" 
Nowadays, the family and community involvement is weakening in the production and use of some plants which are of medicinal values. The small herbs such as tulsi (sacred basil or ocimum sanctum), bojho (sweet flag or acorus calamus), ghodtaapre (Indian pennywort or centella asiatic), pudina (pepper mint or menthe piperita), titepati (mugwort or artemisia dubia wall) and trees such as neem (azadirachta indica), bel (wood apple or aegle marmelos), harro (chebulic myrobalan or terminalia chebula), barro (beleric myrobalan or terminalia bellirica), amala (emblic myrobalan or emblica officinalis), bar (banyan tree or ficus benghalensis) and pipal (ficus religiosa) used to be very important to the village life. According to a participant who is an NGO worker said, "If we do not take it seriously, many of our herbal practices would be a thing of past. There should be programs to promote medicinal herbs. We must raise awareness and promote their cultivation in the families. Distributing medicinal plants (such as tulsi) is like giving net and distributing free medicines (such as tablets) is like giving fish."

The elderly people expressed their worries about the vanishing local health culture and traditions. They provided examples of change in every aspect of culture and tradition: housing pattern, fashion style, tattooing and body piercing, farming and food habit, family and relationship between family members, marriage and sex life, childbearing and rearing, education and health practices. They also expressed that they used to collect various types of yams and wild vegetables and harvest sufficient fish from river and irrigation ditches. They expressed that after the excessive use of chemical fertilizers and pesticides, they are getting fewer crabs, snails and fishes. They also reported increased temperature, insufficient and untimely rainfall, increased insects and mosquitoes, and new diseases. They used to collect wild vegetables and fruits, plants, animals and natural products and use as medicines for various ailments. Now, there are less people who know medicinal herbs and those who know, have little knowledge. The herbal illiteracy is increasing with the modern education system because the school books do not contain chapters on the medicinal plants and their usages.

\section{Change: What is gained and what is lost}

Some participants are of the view that the awareness of personal hygiene and environmental sanitation has been raised in the villages. 


\section{6| Bamdev Subedi}

They said that people get sick not only because of evil spirits but also because of unhygienic or stale food, contaminated water, smoke, dust and dirt. They also placed importance to healthy habit and hygienic behavior, such as washing hands before and after taking foods, avoiding stale food, keeping food away from housefly, and drinking boiled and purified water. They also referred to the excessive use of chemicals and fertilizers in the agricultural fields and contaminated and poisonous food. They were also aware of and concerned about the changes in the food practices.

One of the participants in a group expressed, "Now we have roads and vehicles, and we don't have to carry loads on our back. We have rice and wheat mills, and we don't have to use traditional dhiki and janto. We have tractors running here and there and we don't have to plough oxen. We don't have to go to Koilabas [a trading place at Indo-Nepal border] for salt and kerosene because we have shops in the village and we have connected electricity. We don't have to go to the jungle to collect fodder and firewood because we have started to grow grass here in our fields and we have biogas plant for cooking. We don't have to fetch water from far river because we have tube well and tapped water. Now, we can watch televisions, use mobiles, ride motorcycles, and can buy many things in Ghorahi bazaar. We have schools, health posts, hospitals, banks and buses. We have all the facilities, but [stopped for a while] but we are not healthy than our forefathers (sukhi chhaun tara swostha chhainau)." The meaning was that the modern change and development has made life easy and comfortable but not healthy. The development and economic progress may not necessarily result in better health. The better economic conditions achieved at the cost of health cannot be considered progress.

One of the participants who was in security service emphasized, "We used to be known as bir Nepali (Brave Nepal), bir Gorkhali (Brave Gorkha) because we were bahadur (courageous) to fight fearlessly. Our forefathers were strong and had fought bravely against the British Army. Now we are neither strong nor can we fight. We are rogi (diseased), and we need to take medicines to survive. Some of us take pills for pressure (which he was also taking), some take for diabetes, some for thyroid, some asthma, epilepsy, stress and so on. Most of us will be taking tablets/drugs until our days come." 
Some other participants expressed the similar views and added the name of disease their relatives or neighbors were suffering from. The participant further stated, "Long ago King Prithivi Narayan Shah, the founder of the modern Nepal, in Dibyopadesh stated that Praja mota bhaya darbar baliyo hunyach ha (If citizens are strong and healthy, the monarchy becomes strong). Unfortunately, neither citizen became strong and healthy nor the monarchy.

A participant, who was a college teacher, argued, "Our fathers and grandfathers did not use chemical fertilizers because at that time these things were not introduced. This means our forefathers used to produce and consume organic vegetables and grains. Now, very wealthy few can afford organic products because they are either unavailable, if they are available they are costly." He questioned, "Tell me, who is living higher standard those who consumed organic or those who are consuming inorganic foods?" He also pointed to the effect of kamjori (bodily weakness), "In the times of our fathers and grandfathers, people used to work whole day carry a heavy load on their back. They had the stamina and didn't feel tired so soon. Look at the working people of our time, they just get tired and need a rest in every one or two hours." He referred to the agricultural laborers who habitually take a break for smoking and drinking. In response to the extended life expectancy and the things which have made life easier and comfortable, he argued, "If you live few more days in ICU or ventilator does it make sense?" He is pointing to the quality of lives. Surely, he meant "the life prolonged in ventilator can't be productive and happy life."

\section{Discussion}

The family is the most important institution to handle a wide range of health problems. However, the narratives point to the erosion of family knowledge system which is a grave concern. Home based remedies are undoubtedly the most popular and most accessible source of health care. Most families inherit the skills and experience of dealing with a variety of health problems. The family is the first resource and the role of family continues during and even after the consultation of healers or medical practitioners or the doctors. With the growing health problems and rising chronic disease conditions the role of families as health resource (to promote, restore and maintain 


\section{8| Bamdev Subedi}

health of family members) have become even more important. As most of the healing activity takes place in homes (Kleinman, 1978, 1980), an enhanced family knowledge can contribute to family health and also to achieve health goals. The enhancement of local knowledge base is crucial for a sustainable health. This shows a need of revitalization of local health traditions (Payyappallimana, 2013; Payyappallimana \& Hariramamurthi, 2012; Priya, 2013).

The local health practices are being displaced, disregarded, neglected and disappearing because they are not given importance and incentives. The oral tradition of transmitting healing knowledge from older generation to the younger ones has been slowed down. As a result, the knowledge and practices of using local herbs which are safe and efficacious and have no side effects are also falling. The use of home based herbal preparation is being replaced by the use of manufactured drugs. The dependency on home remedies and local healers is gradually declining whereas use of over the counter drugs is rising with the expansion of health clinics and dispensaries. The younger generation has been demotivated because of disincentives to learn and practice indigenous systems. This is mainly because of lack of state's support. Consequently, there is a threat of losing the local indigenous knowledge base.

In the name of development, embracing Western ideas and technologies can be detrimental. So, an issue is to become sensitive to the situation and critical to the current development, which welcomes Western ideas and technologies, which leads to the dependency and increased health care cost. The narratives of changing crop patterns and use of agricultural inputs signals to losing of local varieties and the rising costs of improved varieties of seeds. The same has been experienced in the local health traditions. On the one hand they are losing local health traditions and the indigenous knowledge base. On the other, they are finding modern health care services costly and unaffordable. Moreover, the modern system does not correspond to the people's perceptions.

It is important to note on why they perceive that they are unhealthy than their forefathers, why they think they are becoming weaker or becoming incapable of digesting the food they eat. Why they have to visit health post and hospitals more frequently, even though 
they do not like to visit. Certainly this is in contradiction with the present achievement of increased level of education, increased life expectancy and decreased mortality. Why are they not satisfied with their health? What is missing? Are we really measuring people's health and well-being? These are some of the issues to reflect on.

A study by Nichter (2005) also points to the declining state of health experience of the people of South Kanara in India. They told that the effectiveness of herbal medicine is falling over the years and that is mainly because of the changes in dietary habits, increased use of biomedical drugs and decreased potency of herbal medicine due to chemical fertilizers. The analogy between biomedicine and chemical fertilizers or biomedicine and eye glasses truly represents the perception of the people under study. The general perception is that once strong biomedical drugs used, the body does not "take to" [soft] herbal medicines and the increased use of strong biomedical drugs does not make a body healthy (Nichter, 2005, p. 212).

A study by Gaur and Patnaik (2011) shows the loss of experiential health and the health threatening conditions among the Korwa tribes in India. The Korwa experienced the loss of health after displacement and resettlement from their natural habitat (Gaur and Patnaik, 2011). The people of our setting expressed the similar situation not because of displacement and resettlement but because of other external factors which are bringing the similar conditions into the villages. So, the subject calls for further research to look into the linkages between the external macro factors and their impact on the lives of local people.

The local people also referred to the increased number of patients, larger crowd, and longer queues in local healers' home, health post and hospitals. They are of the view that the increased flow of patients in clinics and hospitals is not because of health awareness or health consciousness or changes in health seeking behavior but because of an unhealthy population. They attribute it to the food practices, changing crop varieties, use of chemical fertilizers and pesticides, polluted environment, changing climate and arrival of new diseases. The over crowd of patients, according to them, is mainly because of frequent health problems and rising unhealthy population. They believe that healthy population does not need routine and repeated 


\section{0| Bamdev Subedi}

hospital visits. A question arises, has the actual number of patients increased and the total number of visits per person gone up over the years? This needs a serious reflection and further research.

The local worries about the non-availability of medicinal plants and herbs, about fish and crabs, wild animals and birds, farm and forest products are something we should not overlook. The local experience can help us to look at the other side which might be important to understand increased health hazards and threats of the climate change. The decreasing enthusiasm among the healers, demotivation of the youth, greater economic pressure, and vanishing volunteerism are some of the impacts of recent changes. Government policies and programs do not take indigenous practices into consideration nor are there programs in place to prevent the loss of local health traditions. The local indigenous practices are not considered in the formal health care system, even though people largely rely on them. Consequently, the rural people are experiencing a change where on the one hand local health practices are vanishing and on the other, they do not have a viable alternative. The question is whether or not to recognize the importance of local health traditions, prevent them from further damage and create an environment to revitalize them.

\section{Conclusion}

The paper has highlighted the deteriorating health experience of people which has resulted primarily from the loss of local health traditions. Today, local people are going through a rapid change in every aspect of life. Health is one such aspect, and it is interlinked with many others, as evidenced from the reporting of changes in agricultural production, food practices, repeated experience of ill health, excessive use of biomedical drugs and iatrogenic effects, mounting out of pocket health spending, withered family health practices. The situation calls for further exploration about the loss of experiential health of local people in connection with macro changes that have been taking place in the urbanizing villages. The local health practices are also undergoing a change and the pace of change has been accelerated by the increased connectivity, interaction and interventions. The local concern is to prevent local health practices from further damage and mitigate the impact of adverse change and development. The loss of experiential health and declining of local 
health tradition needs a serious reflection. The overall health goal is to "Ensure healthy lives and promote well-being for all at all ages." The health and development programs must consider the measures to revitalize local health traditions to reclaim the local knowledge, to regain the health and to meet the health goals.

\section{Acknowledgements}

I would like to thank all the study participants who shared their experiences generously. I would also like to thank Dr. Sunita Reddy, Jawaharlal Nehru University, New Delhi for her encouragement and support throughout the study. I am grateful to Laxmi Raj Joshi and Krishna Raj Panta for their insight and inputs. I especially thank the anonymous reviewer for the comments which greatly helped to shape the paper in this form.

\section{References}

Bode, M., \& Hariramamurthi, G. (2012). Integrating folk healers in India's public health: acceptance, legitimacy and emancipation. Anthropology and Medicine, 22(1), 23-33. http://dx.doi.org/10.1080/13648470.2015.1005285

Budhathoki, C. B., \& BC, R. K. (2008). Perceptions of Malaria and pattern of treatment seeking behaviour among Tharu and Pahari communities of Jhalari. Journal of Nepal Health Research Council, 6(2), 84-92.

CBS. (2012). National Population and Housing Census 2011

(National Report). Kathmandu: Central Bureau of Statics, Government of Nepal.

CBS. (2014). Nepal in Figures 2014. Kathmandu: Central Bureau of Statics, Government of Nepal.

CBS, \& UNFPA. (2007). Population Profile of Nepal (Published on the World Population Day 2007). Kathmandu: Central Bureau of Statistics.

Kleinman, A. (1978). Concepts and a Model for the Comparision of Medical Systems as Cultural Systems. Social Science \& Medicine, 12, 85-93.

Kleinman, A. (1980). Patients and Healers in the Context of Culture: An Exploration of the Borderland between Anthropology, Medicine and Psychiatry. Berkeley: University of California 
Press.

MoHP, GoN, New ERA, \& ICF International. (2007). Nepal Demographic and Health Survey 2006. Kathmandu, Nepal: Ministry of Health and Population, New ERA, and ICF International, Calverton, Maryland.

NPC, \& UNDP. (2013). Nepal Millennium Development Goals Progress Report 2013. Kathmandu: Government of Nepal, National Planning Commission / United Nations Country Team of Nepal.

NPC, \& UNDP. (2014). Nepal Human Development Report 2014: Beyond Geography, Unlocking Human Potential. Kathmandu: National Planning Commission, Government of Nepal and United Nations Development Program.

Payyappallimana, U. (2013). Health and Well-being in Indian Local Health Traditions. In An Integrated View of Health and Well-being: Bridging Indian and Western Knowledge. Antonio Morandi and A.N. Narayanan Nambi, eds. (Vol. 5, pp. 99-112). New York: Springer. http://dx.doi.org/10.1007/978-94-007-6689-1_7

Payyappallimana, U., \& Hariramamurthi, G. (2012). Local Health

Practioners in India: Resilience, Revitalization and Reintegration. In Medical Pluralism in Contemporary India. V Sujatha and Leena Abraham, eds. Hyderabad: Orient Blackswan Pvt. Ltd.

Priya, R. (2013). The Status and Role of AYUSH and Local Health Traditions in Public Health. The Newsletter, 65, 24-25.

Priya, R., \& Shweta, A. S. (2010). Status and Role of AYUSH and Local Health Traditions under the NRHM. New Delhi: National Health Systems Resource Center.

Saudiyar VDC. (2010). Saudiyar Gabisako Bastusthiti [A Profile of the Saudiyar VDC]. Dang, Nepal: Office of the Saudiyar Village Development Committee (VDC), Dang.

Subedi, M. (2002). Explanatory Models of Food, Health and Illness Ideology in Newar Town of Kirtipur. In Vegetation and Society.R.P. Chaudhary, B. Subedi, T. Aase and O.Vetas, eds. (pp. 228-239). Kathmandu: Tribhuvan University, Kathmandu and University of Bergen, Norway.

Subedi, M. (2011). Illness Causation and Interpretation in a Newar Town. Dhaulagiri Journal of Sociology and Anthropology, $5,101-120$. 
Suvedi, B. K., Pradhan, A., Barnett, S., Puri, M., Chitrakar, S. R., Paudel, P., ... Hulton, L. (2009). Nepal Maternal Mortality and Morbidity Study 2008/2009: Summary of Preliminary Findings. Kathmandu: Family Health Division, Department of Health Services, Ministry of Health, Government of Nepal.

UNDP. (2010). Human Development Report 2010: 20th Anniversary Edition: The Real Wealth of Nations: Pathways to Human Development. New York: United Nations Development Program.

UNDP. (2011). Human Development Report 2011: Sustainability and Equity: A Better Future for All. New York: United Nations Development Program.

UNDP. (2015). Human Development Report 2015: Work for Human Development. New York: United Nations Development Program.

WHO. (2015). Health in 2015: from MDGs, Millennium Development Goals to SDGs, Sustainable Development Goals. Geneva: World Health Organization.

World Bank. (2016). World Development Indicators 2016. Washington DC: International Bank for Reconstruction and Development/The World Bank.

Subedi, Bamdev is a social scientist with an interest in public health issues. He has worked on the issues of HIV/AIDS and STIs, leprosy and disability, personal hygiene and community sanitation, and primary health care in Nepal. He is particularly interested in the local health traditions, Asian medical systems, medical pluralism and political economy of health. Mr. Subedi received his Master's degree in Anthropology in 1998 from Tribhuvan University, Kathmandu and his M.Phil in Social Science in Health in 2013 from Jawaharlal Nehru University (JNU), New Delhi. Currently, Mr. Subedi is a Ph.D. Scholar at the Center of Social Medicine and Community Health, Jawaharlal Nehru University pursuing his research on medical pluralism.

Email: bamdevsubedi@gmail.com 